\title{
Readiness for School, Time and Ethics in Educational Practice
}

\author{
Agnieszka Bates $^{1}$ (D)
}

Published online: 26 November 2018

(C) The Author(s) 2018

\begin{abstract}
'Taking time seriously' is an enduring human concern and questions about the nature of time bear heavily on the meaning of childhood. In the context of the continuing debates on readiness for school, 'taking time seriously' has contributed to policies on 'early interventions' which claim to support children in reaching their full potential but limit this potential when enacted in practice. Much of current policymaking takes the meaning of time for granted within a 'quantitative' view of time as a neutral, standardised parameter. In everyday educational practice, this view of time may lead to an excessive preoccupation with assessing standardised characteristics of 'school ready' children, who are expected to follow a uniform path of development predetermined by their biological clock. However, the quantitative view of time has been challenged both in philosophical and scientific thought by an understanding of time as complex, irreversible and emergent in the present. George Herbert Mead's 'philosophy of the present' and Ilya Prigogine's 'arrow of time' point to important implications of a 'complex' view of time for readiness for school as an event rather than a fixed set of characteristics that children should possess upon entry to primary school. Engaging in educational practice as it unfolds in the present also calls for ethics that are not focused on adhering to fixed moral universals but on our actions "here and now' and attending to the ethical meaning that arises in children's responses to our actions.
\end{abstract}

Keywords Readiness for school · Time $\cdot$ Ethics $\cdot$ Complexity $\cdot$ G.H. Mead · Prigogine

Children only get one chance at education and every child deserves the opportunity to reach their full potential... childhood is short, and when it comes to a child's education, there's no time to waste.

(Nicky Morgan, Department for Education 2016a, p. 4)

\section{Introduction}

The concern about time articulated by the former English Education Secretary Nicky Morgan is shared by policymakers in many countries. The idea that 'there's no time to waste' often surfaces as an 'urgent' need to reform education and 'swiftly' tackle 'underperformance' (DfE 2016a). In the international policy space, every 3 years the 'ticking

Agnieszka Bates

agnieszka.bates@uea.ac.uk

1 School of Education and Lifelong Learning, University of East Anglia (UEA), Norwich, UK 
clock' of PISA confers prestige on education systems whose 15-year-olds have 'outperformed' others in the Programme for International Student Assessment (OECD 2015). In the UK, a poor PISA result generates intense media pressure to improve, with headlines such as: 'Clock ticking for Welsh schools with just two years until Pisa tests' (Evans 2013) and 'Pisa: 'Five years left' to save Scottish curriculum after shocking result' (Seith 2016). In 2017, the Organisation for Economic Co-operation and Development (OECD) developed a new international comparative study centred on assessments of five-year-olds within four domains of: 'emerging literacy, emerging numeracy, self-regulation, empathy and trust' (OECD 2017, p. 17). Motivated by belief in 'early intervention', this new 'baby PISA' (Pence 2017; Moss and Urban 2017) has drawn early childhood into a global standardised assessment regime that is unable to see children's educational experience 'through any other lens than the one provided by PISA' (Urban 2017, p. 20). In this context, time of which there is none 'to waste', becomes a pedagogical resource from which maximum performance has to be extracted to ensure predetermined future benefits.

A focus on a predetermined future also underpins traditional definitions of readiness for school that identify children's developmental capabilities, considered crucial for a smooth home-school transition, such as age-specific social, emotional and motor development, language, cognition and learning skills (Kagan et al. 1995). More recently, the United Nations Children's Fund (UNICEF) has tried to shift focus from children's capabilities to caring environments that enhance a more holistic development of the child. This broader approach, informed by socio-cultural theory (Gardiner and Kosmitzki 2002; Rogoff 2003), views readiness for school as a 'good start in life', within nurturing, safe environments that enable children to be 'physically healthy, emotionally secure, socially competent and able to learn' (UNICEF 2012, p. 6). However, a reductive concern about children's capabilities at the time of home-school transition prevails in countries where policymakers prioritise a quantitative view of time, captured here through the metaphor of the 'ticking clock' of PISA. ${ }^{1}$ In the USA for example, actions taken in response to the recommendation by the National Educational Goals Panel (1991, p. vi) that, by the year 2000, 'all children in America will start school ready to learn' have included opening a governmentfunded Office of School Readiness (Alabama) to get four to five-year-olds 'school ready'. In England, readiness for school has been reduced to 'baseline assessment', a single score of children's performance in communication, language, literacy and mathematics, carried out in the first weeks of school and used to monitor future performance (DfE 2014, 2017). These approaches rely on 'early interventions', in the belief that 'earlier is better' and that intervention requires a formal, centrally designed curriculum to be 'transmitted and formally assessed' (Bingham and Whitbread 2012, p. 14). Children are assumed here to follow a uniform path of development, predetermined by their biological clock and captured by the dominant discourse of developmental psychology (Wood and Hedges 2016). Within these debates, school readiness has thus been conceptualised either as a fixed set of characteristics of 'school ready' children or as the 'appropriate' socio-cultural contexts and relationships that enhance the development of such characteristics. ${ }^{2}$ Both of these

\footnotetext{
1 The metaphor of the 'ticking clock' of PISA is used in this paper to represent 'quantitative' time and associated imperatives of speed, urgency, and acceleration of time. These meanings are also connected to 'clocking practices' in early childhood education (Pacini-Ketchabaw 2012) and the material-discursive significance of the clock as 'an apparatus' that produces particular material effects in Early Years classrooms.

2 There is no scope to detail here the long history of debates on school readiness since tests of 'reading readiness' were introduced in the USA in the 1920s as a measure of children's overall 'readiness' to start school (May and Campbell 1981). School readiness gained renewed attention in the $1990 \mathrm{~s}$, with models
} 
conceptualisations, however, impose ostensibly 'objective' attributes and temporal boundaries which are abstracted from time as subjectively 'lived'. By reducing the complexity of 'temporal matters' (Alhadeff-Jones 2017) to the logics of urgency, speed and 'early intervention', they limit the way time may be experienced and learned by children. In elevating efficient time management and performance outcomes to fixed moral universals, they also give rise to instrumentalist relationships in educational practice.

This paper sets a path yet to be fully explored in contemporary notions of readiness for school by examining their underpinning view of time. It also seeks to contribute to the study of time in education, which continues to be a 'fragmented and underdeveloped scientific territory' (Alhadeff-Jones 2017, p. 33). Looming large in the current debate on readiness for school has been the Enlightenment view of the child as innocent, malleable and ready to mature with time (Hendrick 1997; Ryan 2011). To better understand the idea of children's readiness to mature with time, we therefore need to examine the notion of time itself and the predominant view, from the Enlightenment period onwards, of time as a universal, neutral parameter, divided into equal portions of itself in the form of standardised units such as hours, days, weeks or years. Although this most basic, 'quantitative approach' to time (Bouton 2014) has been developed outside our subjective lived experience, it imposes on us the standardised regularity of the 'ticking clock', as well as the prediction and control of the Enlightenment's scientific-rationalist thinking. 'Quantitative' time as an independent variable of classical physics is reversible: given appropriate initial conditions, classical Newtonian equations can be used to predict the future and 'retrodict' the past. However, an essential premise of prediction and 'retrodiction' is that complexity is reduced and important contextual features are ignored. With the exception of simple mechanistic systems, most aspects of the world are complex and questions about the meaning of time have produced a number of diverse answers, both within philosophical and scientific thought. Philosophical thought offers 'at least five possible strategies... to confront the problem of time' (Bouton 2014, p. 3). In 'confronting' this problem, this paper explores a 'complex' view of time developed by the philosopher, George Herbert Mead and the complexity scientist, Ilya Prigogine. Mead and Prigogine were preoccupied with 'taking time seriously' (Mead 2002, p. 184) and arrived at conclusions that have important implications for understanding readiness for school and for ethics in educational practice. Mead's (2002) 'philosophy of the present' and Prigogine's (1996) 'arrow of time' view of time as complex, irreversible and emergent show ways in which children's readiness for school is bound up with schools' readiness: the degree to which schools are ready to respond to children's needs and capabilities 'here and now'. But let us first focus on different explanations of the nature of time and how they bear on the meaning of childhood.

Footnote 2 (continued)

of school readiness and transition to school developed by Meisels (1999) and Rimm-Kaufman and Pianta (2000) respectively. Meisels developed a standardised assessment of school readiness to help identify gaps and interventions whilst Rimm-Kaufman and Pianta identified the qualities of the teacher-parent relationships necessary for supporting children's adjustment on transition to school within a more dynamic, 'ecological' perspective. 


\section{The Nature of Time and the Meaning of Childhood}

Confronting the enduring question about the nature of time may involve 'at least five strategies' (Bouton 2014, p. 3). The most basic, 'quantitative' strategy goes back to Aristotle's explanation of how time and motion define each other. Time, in Aristotle's view, is measured by regular motion which becomes a standard for measuring all other movement. This means that 'it is not time that measures movement but a certain regular movement that measures all other movements by way of temporal mediation' (p. 4). Whilst the quantitative approach has proved extremely useful in science and daily life, it falls short of explaining the nature of change other than movement. It does not get at the nature of time, because it is placed outside of our experience as lived:

As banal an experience as boredom suffices to bring out the extent to which measurable time does not exhaust the reality of time: there are minutes that last for hours and inversely... In reality, I never measure time but only the consciousness I have of it. (Bouton 2014, p. 5)

Our experience of time as lived resists 'objective' measurement and highlights the importance of the 'subjectivist approach', which defines time in terms of consciousness. The subjectivist view of time (advanced by Kant, Husserl, and Bergson, discussed below) illuminates time as experienced, but at the price of 'wordly' time, the time of nature that transcends the finite human subjectivity. Here, Bouton notes three strategies that transcend the objectivist-subjectivist dichotomy. Firstly, within Hegelian dialectics, time arises both in nature and human consciousness. For Hegel (1970, p. 257) time is not an abstraction that is external to nature and to consciousness: 'Things are in time because they are finite; they do not pass away because they are in time, but are themselves that which is temporal... It is therefore the process of actual things that constitutes time'. Secondly, Heidegger (1962) sought to grasp time in all of its facets as 'temporality', pertaining to being in the world that encompasses both human being (Dasein) and non-human being. For Heidegger, time is the limit of all understanding of being and being can only be understood 'with time as its standpoint' (Bouton 2014, p. 11). Importantly, Heidegger posited that we can only understand time from our mortal, finite vantage point or, in other words, the meaning of time is laid bare in death. Thirdly, Ricoeur (1988) has offered a way out of the 'maze of temporality' through narrative, whereby narrating an event is an act of 'reinscribing a fragment of lived time in the universal calendar of the time of the world' (Bouton 2014 p. 12). However, as noted by Bouton, approaching time from the standpoint of narrative leaves the 'blind spot' on the temporality of action. Bouton therefore suggests another approach to understanding time, which explores the ways in which freedom to act relies on the capacity of time 'to be modified and configured by freedom' (p. 15). The problem of time is thus not just that of its nature but also of the relation between freedom and time. Once the link between time and causal determinism is severed, time becomes the 'auxiliary of freedom' (p. 209). The essential condition of freedom is:

...the plasticity of time. If time is entirely subject to causal determinism, freedom is an illusion... freedom presupposes a contingent future, composed, in what concerns human acts, of possibilities that might or might not transpire. (p. 210)

In exploring the connection between time and freedom, Bouton draws on the work of Levinas (1987), highlighting how one's freedom is about creating possibilities for 
oneself and for others, over whom one has no control. This can be illustrated through the relation of parenting:

The child is at once my child, the child of my flesh, a being in whom I find myself, who concerns me, for whom I am responsible, and a stranger, a being who is not my creature, who escapes my control and is destined to leave me. The future of the child is beyond my possibilities, beyond my projects. (Bouton 2014, p. 243)

These diverse approaches to time bear heavily on the meaning of childhood and the notion of readiness for school. The quantitative time underpins psychological theories of child development and definitions of readiness for school as emotional, cognitive and developmental characteristics possessed by children upon entry to school. Developmental psychology produces ontological propositions, such as that until children have achieved the expected level of development for their age, they are not ready for tasks associated with the next level (Kagan and Rigby 2003). Such propositions fix readiness for school and narrowly focus educational practice on its assessment. In the context of ongoing debates about assessing readiness for school (Dockett and Perry 2002; Kagan and Rigby 2003; Snow 2006), Bingham and Whitbread (2012) emphasise their lack of consensus about the purpose of early education. For Bingham and Whitebread (2012, p. 6), the key question is not 'whether a child is ready to learn' but 'how adults can best support the processes of learning'. The question, therefore, is not what children need to know or be able to do when they start school, but what schools need to do to meet the needs of children. This re-formulated question about the readiness of schools (Fabian and Dunlop 2002) has been addressed in countries such as Finland, Norway and Sweden through 'social pedagogy', which supports children's social, emotional and intellectual development in ways that are firmly embedded in multiple social contexts (Bingham and Whitbread 2012).

However, both readiness for school and readiness of schools run the risk of exhausting themselves in pursuit of more accurate ways of assessing 'objective' attributes of 'school ready' children or characteristics of schools that are ready to meet the children's needs. A closer scrutiny of the 'rival paradigms' of developmental psychology and social pedagogy suggests that both paradigms may be seen as the 'same field of practice', where 'children become means to imagined or envisioned ends' (Ryan 2011, p. 450). By tracing the development of Rousseau's ideas about the education of Émile, Ryan notes how both Émile's tutor and a modern child-centered educator may remain 'invisible', so that:

the child at play was to feel free while unknowingly undergoing a programme of training, the strategic aim of which was to produce self-regulating individuals who identified with a common [social] purpose. (p. 449)

The future of the child is thus confined within the projects of developmental psychology and social pedagogy and the adult mindset in which they originate. However, the 'subjectivist' perspective on time is a reminder that adults can, at best, only have a partial understanding, coloured by their own perspective, of what it means to be a child. Within this perspective, the notion of childhood as a time during which children simply lack adults' categories for analysis and 'differentiation' has been challenged as follows:

Do we have the right to comprehend the time, the space of the child as an undifferentiation of our time, of our space, etc.? ... This is to reduce the child's experience to our own (Merleau-Ponty 1968, p. 203)

Childhood may thus be 'short' for policymakers and teachers concerned with the 'urgent' need to reform education, but the resulting use of time as a resource not to be 'wasted' 
may lead to 'clocking practices' (Pacini-Ketchabaw 2012) that compress the time devoted to class activities and put children in a state of constant mobilisation. Even within adult time-space, regimes that valorise speed in pursuit of 'maximum output in the minimum time expended' (Adam 2006, p. 124; Olma 2007) have also been reported to result in 'distress at work, tiredness, exhaustion, depression [and] burnout' (Alhadeff-Jones 2017, p. 150).

From the standpoint of Hegelian dialectics, despite opposing definitions of readiness for school, as a set of characteristics of 'school ready' children or the contexts in which such characteristics develop, childhood has continued to be instrumentalised 'toward the perpetuation of a selfsame future' (Lakind and Adsit-Morris 2018, p. 32). This instrumentalist framing has been reflected in the 'hegemonic educational temporalizations and paces' of schooling (Papastephanou 2018, p. 97), deployed to predetermine, measure and control learning and its future outcomes. In this context, situating educational practice more firmly in the 'here and now' is important not as a 'disavowal of the future, but of future-orientations that negate children as bearers of their own experience and agents of their own purpose' (Lakind and Adsit-Morris 2018, p. 36). To recover the present in educational practice, this paper now turns to Mead's (2002) 'philosophy of the present' and Prigogine's (1996) explication of the 'arrow of time'.

\section{Prigogine's 'Arrow of Time' and Mead's 'Philosophy of the Present'}

Mead's 'philosophy of the present' (1932/2002) has strong resonances with the complexity science view of time as unidirectional (irreversible), as captured by Prigogine's (1996) metaphor of the 'arrow of time'. The 'arrow of time' emphasises the irreversibility of many processes that complex systems undergo as a result of fluctuations, instability and multiple choices, in contrast to classical Newtonian mechanics, where time is a neutral parameter, a universal dimension 'common to all observers' (Prigogine 1996, p. 164). The regularity, order and stability expressed in classical mechanics in the form of time-reversible equations correspond to 'approximations' or 'idealizations', for example friction is ignored to make the pendulum move reversibly (p. 18). This approximation is problematic for Prigogine, because there is no absolute void (and consequently no frictionless condition) in nature. Although nature involves both time-irreversible and time-reversible processes, the former are the rule and the latter the exception. The irreversible, time-oriented processes that Prigogine investigated are characterized by increasing entropy, defined as a number of states into which a system may evolve over time. In classical physics, preoccupied with closed systems, i.e. systems isolated from the environment, in states close to equilibrium, entropy is viewed as a loss of a system's thermal energy that is subsequently unavailable for doing useful work. Prigogine, on the other hand, studied the workings of 'dissipative structures', i.e. open systems in which there is an exchange of energy and matter with the environment. His definition of dissipative structures encompasses many open systems which are maintained by continuous flows of energy, such as chemical reactions, ecosystems and human social behaviour. Irreversibility means that it is impossible to undo the effects of certain chemical reactions: once 'mixed' together, the original molecular structures cannot be 'un-mixed'. Similarly:

You cannot reverse the evolution of the universe, even theoretically, and you cannot deduce or reproduce the past. You cannot predict its future, except in terms of 
scenarios that depend on a never-ending series of bifurcations - crossroads in the chain of causality. (Prigogine 1983, p. 86)

The 'arrow of time' entails that the future of open systems is not given, but is under perpetual construction and, therefore, 'no formulation of the laws of nature that does not take into account this constructive role of time can ever be satisfactory' (Prigogine 1996, p. 56). As a scientist interested in philosophy, Prigogine thus emphasises that, contrary to classical science descriptions of present and past as identical and reversible and the world as a static, 'timeless automaton', our everyday experience tells us that 'tomorrow is not contained in today': in our everyday life, we experience activity, change (Prigogine 1982, p. 25). The question about what the flow of time 'preserves, creates and destroys' is a central human concern (Prigogine 1996, p. 154). As a philosopher interested in science, Mead (2002) started with investigating how time is experienced in our everyday life, arriving at answers about the nature of time that resonate with Prigogine's explanations of the 'arrow of time'.

Central to Mead's 'philosophy of the present' is a view of time as irreversible, experienced in the present and rooted in the social nature of the present. Like Prigogine, Mead was also critical of the Newtonian notion of time as a mere parameter. Newtonian time as a 'mere passage', a simple timeline 'divided into equal portions of itself' was for Mead an illusion and example of an 'unwarranted use of abstraction' (p. 332). The range of applications of Newtonian time was, according to Mead, limited to experimental data obtained in tightly controlled (laboratory) environments. Time as experienced in our consciousness in our day to day life is complex, with present, past and future permeating one another and undergoing perpetual reconstruction in the present. Here, Mead worked with the ideas of time and consciousness developed by Henri Bergson (1910) and in particular his idea of 'pure duration' which distinguishes 'quantitative' and 'subjective' time, experienced in consciousness. Pure duration, according to Bergson, is:

the form which the succession of our conscious states assumes when our ego lets itself live, when it refrains from separating its present state from its former states... in recalling these states, it does not set them alongside its actual state as one point alongside another, but forms both the past and the present states into an organic whole, as happens when we recall the notes of a tune, melting, so to speak, into one another... even if these notes succeed one another, yet we perceive them in one another... just because they are so closely connected... (1910 u. 100)

Bergson contrasted this complex view of time with a superficial idea of time where the organic whole formed of past and present states is reduced to a sequence of separate events. Elaborating on this point, Mead maintained that present, past and future are not measurable dimensions, but rather the distinction between them is relational, in the sense that the relation to the present is the ground for the 'past-ness' of the past and the 'future-ness' of the future (Murphy 2002). The key causal relation between past, present and future is that of emergence: the appearance of 'unique events which are distinguishable from each other through their qualitative nature' (Mead 2002, p. 51). In place of Newtonian time as a sequenced, measurable quantity, Mead thus introduced a more dynamic, complex concept of time, inextricably linked with the emergent event:

the occurrence of something which is more than the processes that have led up to it and which... adds to later passages a content that they would not otherwise have possessed. (p. 332) 
Mead's point that the 'world is a world of events' (p. 35) and that time 'can only arise through the ordering of passage of ...unique [emergent] events' (p. 338) resonates with Prigogine's (1996, p. 5) observation that, in order to understand complex systems, 'we need not only laws, but also events that bring an element of radical novelty' to their description.

The present has a 'social' nature through its capacity of being in more than one system, which is termed by Mead 'sociality':

Sociality is the capacity of being several things at once. The animal traverses the ground in pursuit of his prey, and is at once a part of the system of distribution of energies which makes his locomotion possible and a part of the jungle system which is a part of the life system on the surface of the inanimate globe... There is a genuine sociality in his relation to his environment and in his relation to the prey or to his mate or to his pack... (2002, p. 75)

For Mead, change is emergent and emergence is paradoxical: the appearance of a new event, 'from the conditions under which it has appeared' is simultaneously accompanied by the 'carrying on of identical conditions from the past into the present' (p. 75). Similarly, in the passage of time from the past into the future, the present object, such as the animal pursuing its prey, 'is both the old and the new, and this holds for its relations to all other members of the system to which it belongs' (p. 77). In the present, therefore, we simultaneously experience both continuity and change, or as Mead puts it, both the 'old order' and the 'readjustments' of change:

In the history of a community, the members carry over from an old order their characters as determined by social relations into the readjustments of social change... So

Rousseau had to find both sovereign and subject in the citizen, and Kant had to find both the giver of the moral law and subject of the law in the rational being. (p. 77)

The ideas about time expounded by Prigogine and Mead provide a radical departure from the quantitative, Newtonian time as a reversible, independent variable which retains the same quality as other variables change. The special contributions of Prigogine and Mead to the 'strategies' for confronting the question about the nature of time (Bouton 2014) rest on their insights into the primacy of events, emergence, the importance of the present and its social nature ('sociality). The following sections explain how these insights support alternative approaches to readiness for school and educational practice, by focusing on: the present as the locus of reality; 'taking on the role of the other' and ethics in educational practice.

\section{The Present as the Locus for Realising One's 'Full Potential'}

In positing the present as the locus of reality, Mead (1932/2002) emphasised that it is in the present that possibilities emerge to discontinue the past and shape the future in novel ways. In the present, the emergent event creates with its uniqueness both a new past and a new future. On this account, readiness for school can be understood as an event, a process which gradually unfolds in time rather than a fixed, static 'property' that children are assessed to either possess or lack upon entry to school. In the present, a child may gain (or lose) a myriad of chances at learning that arise in ongoing child-teacher interactions. These chances depend both on the child's readiness to learn and the degree of her teacher's readiness to engage with teaching as a dynamic process of constantly producing and readjusting 
a course of action within a situation (Joas 1996) rather than acting to a rigid, predetermined outcome or a fixed assessment of a child's capabilities and needs. The meaning of what I do in my classroom is not fixed in advance though lesson objectives, learning outcomes, or my authority as a teacher, but arises in the children's responses to my actions. Teaching within the quantitative, Newtonian timeframe, conceived as a 'sequence of unitary acts' comprising a uniformly passing reality (Joas and Scharmer 1999, p. 17), for example a series of discrete lessons built into a scheme of work and rigidly delivered to a plan, constrains the creativity of teacher's actions. For Joas, the creativity of action is predicated on noticing the dynamism of the present as it unfolds and challenges our beliefs, taken-forgranted assumptions and routines. ${ }^{3}$ When emergent events shatter our expectations:

Our perception must come to terms with new or different aspects of reality; action must be applied to different points of the world, or must restructure itself. This reconstruction is a creative achievement on the part of the actor. If he succeeds in reorienting the action on the basis of this changed perception and thus continuing with it, then something new enters the world: a new mode of action, which can gradually take root and thus itself become an unreflected routine. (Joas 1996, pp. 128-29)

Children are also capable of creative action, of 'remaking (and not merely receiving) knowledge', as long as the teacher provides conditions under which the future is 'unwritten' and 'open'" (Yarker 2016, p. 30). From the standpoint of complex time, schools' readiness to creatively respond to children's needs and capabilities in the present may, therefore, be more effective in shaping their development than orienting children towards what they will need or should be able to do in the future.

The 'taming' of learning processes and practices through planning, controlling, assessing and evaluating against predetermined goals is underpinned by a view of knowledge as 'stable' (Olsson 2012, p. 89). Young children, however, prefer to stay in the processes of learning and knowledge production rather than to imitate 'stable' knowledge:

Children, when allowed to, seem to enjoy a certain kind of intense, undomesticated, and vital experimentation rather than looking for any kind of permanent and stable knowledge (ibid. p. 89)

Olsson (2012) recommends that teachers develop their everyday practice as a collectively constructed, open-ended process which is sensitive to children's preferences and learning strategies. Crucial to this process are listening and careful observation as ways of sensing the relation that the children already have to the subject and the underlying question: 'What are they after?' (p. 97). Intervention in 'children's doings' should be limited and approached 'very cautiously' (p. 93). Olsson (2012) found that allowing children to experiment, at their own pace, with the 'Magic of Language' led to an 'intensity' of children's engagement, as well as more creative and profound learning than that based on imitation or reproduction.

Mead's view of the present as the locus of reality also challenges the standardised pace and timeline of children's progress through school, with predetermined developmental

\footnotetext{
3 Joas (1996) developed his theory by working with Mead's philosophy of time. There are three elements of the creativity of action as 'the way in which human beings exist in the world': (a) a non-teleological orientation, as a departure from a means-ends thinking, (b) an attitude which embraces both 'spontaneity' (or pre-reflective impulses and perceptions) and reflection, and (c) acting from a recognition of the self and others as interdependent rather than atomised and autonomous (Joas and Scharmer 1999).
} 
milestones such as getting ready for school, transition to primary and then secondary education and preparing 'for adult life' (DfE 2016a, p. 8). This timeline is demarcated by regular assessment activities, as a measure schools' accountability for 'stretch[ing] every child... to reach their full potential' (p. 10). This is based on an assumption that getting children through regular tests will enable them to leave primary school 'with the essential building blocks to succeed at secondary' (p. 20). However, the focus on 'essential building blocks' has proved time and again to be detrimental in education systems where the 'ticking clock' of PISA sets the pace of educational practice. In England, for example, the negative consequences of an excessive focus on testing have included a narrowing of the curriculum, teaching to the test, student anxiety and disaffection (Hutchings 2015). From Mead's standpoint, a more important educational task 'here and now' arises from the implications of 'sociality' for the purpose of education.

\section{Taking on the Role of the Other as the Social Purpose of Education}

As discussed above, 'sociality', or the 'social nature of the present' arises from a simultaneous membership of an agent in multiple systems (Mead 1956, p. 339). As time passes, sociality involves continual readjustment necessary for incorporating emergent events into one's ongoing experience, nested in these multiple systems (Doan 1956; Natanson 1953). Sociality partly resonates with socio-cultural approaches to readiness for school, which see the child, her family and school as embedded within social, cultural and historic influences (Rogoff 2003; Gardiner and Kosmitzki 2002; Pence and Nsamenang 2008; UNICEF 2012). According to these approaches, transition to school involves children adjusting to new learning environments, families learning to work within a sociocultural system of a school and schools making provisions for admitting new children. Mead's account highlights that the school presents for young children an entirely new social world, with a unique system of meaning which may be exciting, anxiety-provoking and at times meaningless. School routines, schedules and rules require an ongoing readjustment and sense-making before they become familiar and meaningful to young children. Making sense of assessment may be even more challenging.

An example of assessment which may be meaningless to young children is Baseline Assessment (BA). BA was introduced in 2015 as a replacement for the Early Years Foundation Stage Profile (EYFSP) and bears strong resemblances with 'baby PISA' (Pence 2017; Carr et al. 2016). The EYFSP was completed through observations of children throughout their first year in school and included a range of areas: communication and language development; physical, personal, social and emotional development; literacy; maths; understanding the world and expressive arts. By contrast, BA is an on-entry test consisting of formal assessment tasks focused on communication, language, literacy and mathematics that result in a single numerical score for each child (DfE 2014). ${ }^{4}$ BA disregards research confirming that children learn best (and best demonstrate their learning) through supportive, collaborative relationships and play activities (Broadhead 2006; Fleer and Richardson 2009). Conducting BA through formal tasks which children complete on entry to school, in new, unfamiliar context is unlikely to allow children to show their 'true potential'. Children

\footnotetext{
${ }^{4}$ Baseline Assessment (BA) was withdrawn in 2017, because the different assessments used by schools were 'not sufficiently comparable to create a fair starting point from which to measure pupils' progress' (DfE 2016b). At the time of writing, BA was reinstated as statutory from September 2020 (DfE 2018).
} 
in their first weeks of school rarely have the confidence to demonstrate their capabilities (Bradbury and Roberts-Holmes 2016). Baseline assessment appears to serve the demands of school accountability rather than children's needs.

An important need upon entering school as a new 'sociality' is for children to learn to 'take on the role of the other', to apprehend what many others may think and feel in response to one's actions (Mead 2002, p. 190). For young children, the development of the ability to understand the attitudes of others starts with listening to stories and imaginative play. Frequent, uninterrupted 'story time' enables children to develop an understanding of others and experience time as subjectively lived (Bouton 2014). Stories invite children to imagine multiple possibilities, enter the attitude of others and immerse in narrative time. As Ricoeur (1980, p. 174) points out, even the simplest story 'escapes' the notion of time conceived of as 'a series of instants succeeding one another along an abstract line oriented in a single direction'. Heard within the familiar, safe classroom space, stories enable children to encounter contingency and unpredictability:

A narrative conclusion can be neither deduced nor predicted. There is no story if our attention is not moved along by a thousand contingencies... So rather than being predictable, a conclusion must be acceptable. (Ricoeur 1980, p. 174)

Class 'story time' is also time for 'being-with-others' (Ricoeur 1980), for sharing in our 'collective vulnerability' (Lakind and Adsit-Morris 2018, p.36). Exploring 'collective vulnerability' is also enabled through free, imaginative play. In contrast to 'structured play' organised around rigid, predetermined goals and rules, free play allows children to 'experiment with vulnerability and surprise in ways that could be distressing outside the play setting, but are delightful in play' (Nussbaum 2010, p. 101). Frequent 'story time' and imaginative play time can be seen as integral to 'pedagogic slow time', time with no prespecified objectives or goals. A school timetable that includes 'pedagogic slow time' could enable children to experience time in ways that transcend the 'ticking clock' time, thereby allowing them to be the 'agents of their own purpose' (Lakind and Adsit-Morris 2018, p. 36).

\section{The Present and Ethics in Educational Practice}

Taking the present as the locus of reality has profound implications for teaching and assessing children as ethical rather than instrumental activities. In the present as the locus of ethical intention, we choose a course of action when our knowledge of the consequences of our actions is always emergent and, therefore, limited and uncertain. Instead of striving for accurate assessment as a basis for predicting uncertain outcomes, teaching could focus instead on apprehending the attitude of children 'here and now'. Working with a complex view of time also means that we need to check the impulse to idealise and to draw away (to 'abstract') from everyday experience. As argued by Griffin (2002, p. 15), the impulse to idealise and abstract from experience reduces ethics to the justification of intention or thought as disconnected from action:

When we locate ethics in the intention, or thought, apart from or before the action, we are assuming that the likely outcome of the action can be known before the action is taken... However, when the intention arises in the action... and when the outcome of the action cannot be known in advance of acting, then a different view of ethics is required. 
In the world of events, ethics emerge in the present and are predicated on action that is 'determined constructively from situation to situation and is open to continuous revision' (Joas 1996, pp. 161-163). Ethical preoccupations thus shift from the question: 'What should I do to ensure that children reach their full potential at a specified point in the future?' to: 'What is it like for this child to experience what is going on in class now?' There are no clear answers to this question predetermined in advance of the actions that we take and the meaning of these actions can only be discerned in the children's responses.

A recognition of the present as a locus of reality calls for ethics that are not focused on adhering to timeless idealisations but on our interactions 'here and now' and the ongoing attending to the meanings of actions that are not known in advance. As Mead (1908, p. 319 ) points out, moral development 'consists not in adapting individual natures to the fixed realities of a moral universe, but in constantly reconstructing and recreating the world' as we evolve. Educational ethics that embrace the present as the locus of reality call for us to be present in our ordinary everyday interactions, for it is in the present that intention, thought, freedom and action are lived through, 'within the constraints of the past, in the process of movement into an unknown future' (Griffin 2002, p. 20). This, in turn, means that the responsibility for enhancing children's educational opportunities is not located in assessment policy or an 'accountability' system, but in everyday choices made by adults who work with children. Importantly, ethics in educational practice arise from a willingness to enter into the attitude of the child and respond to his needs and capabilities 'here and now'. Being responsible for, and responsive to, children is thus about being open to ethical meaning which emerges in everyday practice as it unfolds in the present.

Being responsive also means learning from children (Lakind and Adsit-Morris 2018, p. 37 ) and making education more childlike (Kohan 2015). Kohan draws on Heraclitus' investigation of time as 'aion' (as opposed to 'chronos') and his observation that 'Time [aion] (is) a child childing (playing); its realm is one of a child' (p. 57). Time as 'aion' designates intensity, density and duration rather than successive, numbered movement captured in the conception of time as 'chronos'. 'Aion' entails a dimension of living that is 'more akin to a childlike form of being' with a 'specific strength, force or intensity' (p. 57). 'Aion' is not restricted to childhood as a chronological stage of human life and may be experienced at other times within the human lifespan. 'Childlike' education may be conceived of as a process of unlearning, questioning, experimenting and affirming the importance of not knowing (Kohan 2015). Since the 'intensity' and 'density' of this process are experienced in the present, it is important to distinguish the 'now' of time as 'aion' (time of preoccupation, concern) from the 'now' in the sense of 'chronos' (as an abstract moment in time).

The ethics of being in the present are also concerned with 'here and now' as 'time-space'. For the post-humanist philosopher and theoretical physicist Karen Barad (2007), time is always entangled with place and its 'materiality'. The clock hung on a classroom wall has both metaphorical and material meaning. The metaphor of the 'ticking clock' of PISA represents the dominance of quantitative time and the concomitant imperatives of speed, acceleration and time compression. But the clock also has a material presence in the classroom as an 'apparatus' that constitutes particular meanings, bodies, boundaries, inclusions and exclusions (Barad 2007). The classroom clock produces material-discursive 'clocking practices' that organise the movement of children between distinct, time-bound activities, often disrupting the duration and intensity experienced by children engaged in an activity (Pacini-Ketchabaw 2012). As a result of 'clocking practices', 'different subjectivities materialize... as others are excluded' (p. 158) and 'particular bodies are produced... through which power works its productive effects' (Barad 2007, p. 230). Ethics in educational practice are predicated on the entanglement of time in the 
materiality of the people, place and apparatus. Importantly, we are always already entangled and 'to be entangled is not simply to be intertwined with another, as in the joining of separate entities, but to lack an independent self-contained existence' (Barad 2007, p. ix).

\section{Conclusion}

This paper has focused on the educational implications of time as emergent in the present and irreversible. On this view of time, children's learning is an event that unfolds within everyday practice as an open-ended, dynamic process of constantly readjusting the course of action taken by the teacher. This readjustment takes place in the light of children's responses to her actions rather than predetermined outcomes or a fixed assessment of children's capabilities. The possibilities arising from allowing children to experience duration and intensity through 'pedagogic slow time', open-ended experimentation and free, imaginative play are likely to be of greater value than rigidly-controlled projects that focus excessively on predetermined outcomes. Like the notes of a tune 'melting' into one another (Bergson 1910), time spent at school is an inseparable part of childhood. Reducing school time to a sequence of separate 'building blocks', interventions and formal assessment exercises may disrupt both the intensity of children's engagement in learning and the experience of time as duration, through which school time and home time merge into an organic whole, to create the continuity that is often missing in the fragmented lives of adults (Alhadeff-Jones 2017).

The implications of 'temporal complexity' (Alhadeff-Jones 2017) go beyond changes to school timetables. Understanding temporal complexity requires an engagement with answers about the nature of time within philosophical thought. What comes to light from this engagement is that the enduring dominance of quantitative time within education policy context may have adverse effects on educational practice. Educational practice organised solely around the 'ticking clock' of PISA introduces the logics of urgency, speed and 'early intervention' into the time-space of childhood, potentially contributing to disaffection and anxiety at school (Hutchings 2015). Quantitative time is 'indifferent to human beings, to their acting and their suffering' (Ricoeur 1980, p. 175). It is, therefore, unable to generate more complex meanings in teachers' work and children's learning that go beyond concerns about efficiency and outcomes. Quantitative time fails to measure duration and intensity of engagement in the moment. It excludes the possibility that childhood is not simply a finite chronological stage but a state of strength and force that makes humans more open to not knowing (Kohan 2015). The material consequences of the inclusions and exclusions effected through 'clocking practices' may render them ethically problematic (Pacini-Ketchabaw 2012). In this context, therefore, teachers ought to take a cautious and, if necessary, critical approach to the dominance of quantitative time in policy and practice.

Understanding temporal complexity also requires an engagement with the specific contribution of Mead and Prigogine to enduring discussions about the nature of time. What Mead and Prigogine add to the 'five strategies' for 'confronting' temporal complexity (Bouton 2014, p. 3) are insights into the present as the locus of reality, emergence and the irreversibility of time. The 'arrow of time' is a stark reminder of negative, often unpredictable consequences of actions that cannot be undone. It is also a signpost to a possibility that we may be at a turning point: we are experiencing the continuity of the 'old order' (Mead 2002, p. 77), determined by the scientific-rationalist thinking of the Enlightenment and, simultaneously making 'readjustments' to our understanding of the world in light of 
complexity science. As Prigogine (1996, p. 7) has highlighted, for some time now, we have observed the "birth of a science that is no longer limited to idealized and simplified situations but reflects the complexity of the real world, a science that views us and our creativity as part of a fundamental trend present at all levels of nature'. Complexity science tells us that little is certain about the world in which we live but it is the uncertainty of a contingent future that provides an 'auxiliary to freedom' (Bouton 2014, p. 210). The plasticity of time that Bouton writes about is also an auxiliary to engaging anew with questions about time in education. The question about how children should experience their time in education is entangled with a more general concern about what, as humans, we should or could do with the time that we have to live, in a complex and interrelated world.

Although much critique can be levelled at educational practice that excessively focuses on a predetermined future, this does not mean that education should focus solely on the 'here and now'. Whilst we experience reality in the present, we naturally also pay attention to the past and the future. Reconstructing the past in the light of the present gives us the benefit of hindsight and enhances our understanding. In anticipating the future, we experience emergence as the essence of complex time. The present contains multiple courses of action that can be taken and multiple possible futures that may emerge. However, when a preoccupation with predetermined outcomes becomes the main educational modus operandi, as in policy and practice that frame readiness for school as a measure of future performance, possibilities close down. If there is, therefore, an 'urgent' need for change in education, then it is about a shift from instrumentalist practice which sees children as 'means' to the ends predetermined by adults to educational practice which is more sensitive to children's needs and capabilities 'here and now'. Childhood is indeed short in the timescale of human life but 'taking time seriously' entails that we dwell longer in the present, as if there were time to waste, for it is in the present that educational practice can be merely replicated or approached anew and changed.

Acknowledgements The author wishes to thank the two anonymous reviewers for their constructive, insightful feedback. The author also wishes to show special gratitude to Prof. Nigel Norris and Dr. Geoff Hinchliffe who commented on early drafts of this paper.

Open Access This article is distributed under the terms of the Creative Commons Attribution 4.0 International License (http://creativecommons.org/licenses/by/4.0/), which permits unrestricted use, distribution, and reproduction in any medium, provided you give appropriate credit to the original author(s) and the source, provide a link to the Creative Commons license, and indicate if changes were made.

\section{References}

Adam, B. 2006. Time. Theory, Culture \& Society 23 (2-3): 119-138.

Alhadeff-Jones, M. 2017. Time and the rhythms of emancipatory education: Rethinking the temporal complexity of self and society. London: Routledge.

Barad, K. 2007. Meeting the Universe Halfway: quantum physics and the entanglement of matter and meaning. Durham: Duke University Press.

Bergson, H. 1910. Time and Free Will: An Essay on the Immediate Data of Consciousness (translated by F.L. Pogson). London: George Allen and Unwin. https://brocku.ca/MeadProject/Bergson/Bergs on_1910/Bergson_1910_02.html. Accessed 27 May 2017.

Bingham, S. and Whitbread, D. 2012. School Readiness: A critical review of perspectives and evidence. Croome D’Abitot, Worcs: TACTYC (Association for the Professional Development of Early Years Educators).

Bouton, C. 2014. Time and freedom. Trans. C. Macann. Evanston, Illinois: Northwestern University Press. 
Bradbury, A. and Roberts-Holmes, R. 2016. "They're children... not robots, not machines": The Introduction of Reception Baseline Assessment. https://www.teachers.org.uk/sites/default/files2014/baselineassessment-final-10404.pdf. Accessed 23 Mar 2018.

Broadhead, P. 2006. Developing an understanding of young children's learning through play: The place of observation, interaction and reflection. British Educational Research Journal 32 (2): 191-207.

Carr, M., L. Mitchell, and L. Rameka. 2016. Some thoughts about the value of an OECD international assessment framework for early childhood services in Aotearoa New Zealand. Contemporary Issues in Early Childhood 17 (4): 450-454.

DfE. 2014. Reforming assessment and accountability for primary schools. https://assets.publishing.servi ce.gov.uk/government/uploads/system/uploads/attachment_data/file/297595/Primary_Accountability_ and_Assessment_Consultation_Response.pdf. Accessed 12 Sept 2017.

DfE. 2016a. Educational Excellence Everywhere. Available at: https://www.gov.uk/government/uploads/ system/uploads/attachment_data/file/508447/Educational_Excellence_Everywhere.pdf. Accessed 9 Aug 2017.

DfE. 2016b. Press release: Reception baseline comparability study published. Available at: https://www. gov.uk/government/news/reception-baseline-comparability-study-published. Accessed 5 Mar 2017.

DfE. 2017. Primary Assessment in England: Government consultation. https://consult.education.gov.uk/ assessment-policy-and-development/primary-assessment/supporting_documents/Primary\%20assessme nt\%20in\%20England.pdf. Accessed 5 Apr 2017.

DfE. 2018. Reception baseline assessment. https://www.gov.uk/guidance/reception-baseline-assessment. Accessed 29 Oct 2018.

Doan, F.M. 1956. Notations on G. H. Mead's principle of sociality with special reference to transformation. The Journal of Philosophy 53 (20): 607-615.

Dockett, S., and B. Perry. 2002. Who's ready for what? Young children starting school. Contemporary Issues in Early Childhood 3: 67-89.

Evans, G. 2013. Clock ticking for Welsh schools with just two years until Pisa tests. Wales online (20 June). https://www.walesonline.co.uk/news/wales-news/clock-ticking-welsh-schools-just-4687120. Accessed 4 Apr 2018.

Fabian, H., and A.W.A. Dunlop (eds.). 2002. Transitions in the early years: Debating continuity and progression for children in early education. London: RoutledgeFalmer.

Fleer, M., and C. Richardson. 2009. Mapping the transformation of understanding. In Early childhood education: Society and culture, 2nd ed, ed. A. Anning, J. Cunning, and M. Fleer. London: Sage Publications.

Gardiner, H.W., and C. Kosmitzki. 2002. Lives across cultures: Cross-cultural human development. Boston, Mass: Allyn \& Bacon.

Griffin, D. 2002. The emergence of leadership: Linking self-organisation and ethics. London: Routledge.

Heidegger, M. 1962. Being and Time (Transl. J. Macquarrie and E. Robinson). Malden and Oxford: Blackwell Publishing Ltd.

Hegel, G.W.F. 1970. Encyclopaedia. Vol. 2, Philosophy of Nature. Trans. M.J. Petry. London and New York: George Allen and Unwin: Humanities.

Hendrick, H. 1997. Constructions and reconstructions of British childhood: an interpretative survey 1800 to the present. In Constructing and Reconstructing Childhood: Contemporary Issues in the Sociological Study of Childhood, ed. A. James and A. Prout. London: Falmer Press.

Hutchings, M. 2015. Exam factories? The impact of accountability measures on children and young people. https://www.teachers.org.uk/files/exam-factories.pdf. Accessed 10 Mar 2016.

Joas, H. 1996. The Creativity of Action. Trans. J. Gaines and P. Keast. Chicago: University of Chicago Press.

Joas, H. and Scharmer, C.O. 1999. Action Is the Way in Which Human Beings Exist in the World: Conversation with Professor Hans Joas, Freie Universität Berlin September 21. http://maydaygroup.org/wpcontent/uploads/2014/08/Joas-Action.pdf. Accessed 25 May 2018.

Kagan, S.L., E. Moore, and S. Bredekamp. 1995. Reconsidering children's early development and learning: Toward common views and vocabulary. Washington, DC: National Education Goals Panel.

Kagan, S. and Rigby, E. 2003. Policy Matters: Setting and Measuring Benchmarkd for State Policies. Improving the Readiness for School. A Discussion Paper. Washington DC: Center for the Study of Social Policy.

Kohan, W. 2015. Childhood, Education and Philosophy: New ideas for an old relationship. Abingdon: Routledge.

Lakind, A., and C. Adsit-Morris. 2018. Future child: Pedagogy and the post-anthropocene. Journal of Childhood Studies 43 (1): 30-43.

Levinas, E. 1987. Time and the Other and Additional Essays. (Trans. R.A. Cohen). Pittsburgh: Duquesne University Press. 
May, C., and R. Campbell. 1981. Readiness for Learning: assumptions and realities. Theory into Practice 20 (2): $130-134$.

Meisels, S.J. 1999. Assessing Readiness. In Transition to Kindergarten, ed. R. Pianta and M. Cox, 39-63. Baltimore: Paul H Brookes.

Moss, P., and M. Urban. 2017. The OECD's international early learning study: What happened next. Contemporary Issues in Early Childhood 18 (2): 250-258.

Natanson, M. 1953. George H. Mead's metaphysic of time. The Journal of Philosophy 50 (25): 770-782.

Mead, G.H. 1956. The Social Psychology of George Herbert Mead, ed. Strauss, A. Chicago and London: The University of Chicago Press.

Mead, G.H. 1932/2002. The Philosophy of the Present. New York: Prometheus Books.

Merleau-Ponty, M. 1968. The visible and the invisible. Evanston: Northwestern University Press.

Murphy, A.E. 2002. 'Introduction'. In The Philosophy of the Present, 11-30. New York: Prometheus Books.

National Educational Goals Panel. 1991. The national educational goals report building a nation to learn. Washington: US Government.

Nussbaum, M. 2010. Not for profit: Why democracy needs the humanities. Princeton: Princeton University Press.

OECD. 2015. Singapore tops latest OECD PISA global education survey. http://www.oecd.org/education/ singapore-tops-latest-oecd-pisa-global-education-survey.htm. Accessed 18 Feb 2018.

OECD. 2017. Early Learning Matters. http://www.oecd.org/education/school/Early-Learning-Matters-Proje ct-Brochure.pdf. Accessed 18 Feb 2018.

Olma, S. 2007. Physical Bergsonism and the Worldliness of Time. Theory, Culture \& Society 24 (6): 123-137.

Olsson, L.M. 2012. Eventicizing curriculum: Listening to read and write through becoming a citizen of the world. Journal of Curriculum Theorizing 28 (1): 88-107.

Pacini-Ketchabaw, V. 2012. Acting with the clock: Clocking practices in early childhood. Contemporary Issues in Early Childhood 13 (2): 154-160.

Papastephanou, M. 2018. Michel Alhadeff-Jones, time and the rhythms of emancipatory education: Rethinking the temporal complexity of self and society. Studies in Philosophy and Education 37: 97-102.

Pence, A. 2017. Baby PISA: Dangers that can arise when foundations shift. Journal of Childhood Studies 41 (3): 54-58.

Prigogine, I. 1983. 'Interview with Illya Prigogine by R.B Tucker.' In Omni Magazine. New York: Omni Publications International.

Prigogine, I. 1996. The end of certainty: Time, chaos and the new laws of nature. New York: The Free Press.

Prigogine, I. 1982. 'Only an Illusion', The Tanner Lectures on Human Values. https://tannerlectures.utah. edu/_documents/a-to-z/p/Prigogine84.pdf. Accessed 6 May 2018.

Ricoeur, P. 1980. On narrative. Critical Inquiry 7 (1): 169-190.

Ricoeur, P. 1988. Time and Narrative, Vol. 3: Narrated Time. Trans. K. McLaughlin and D. Pellauer. Chicago: University of Chicago Press.

Rimm-Kaufman, S.E., and R.C. Pianta. 2000. An ecological perspective on the transition to kindergarten: A theoretical framework to guide empirical research. Journal of Applied Developmental Psychology 21 (5): 491-511.

Rogoff, B. 2003. The cultural nature of human development. New York: Oxford University Press.

Ryan, K.W. 2011. The new wave of childhood studies: Breaking the grip of bio-social dualism? Childhood 19 (4): 439-452.

Seith, E. 2016. Pisa: 'Five years left' to save Scottish curriculum after shocking result, Times Educational Supplement (9th December). https://www.tes.com/news/school-news/breaking-news/pisa-five-years -left-save-scottish-curriculum-after-shocking-result. Accessed 4 Apr 2018.

Snow, K.L. 2006. Measuring school readiness: Conceptual and practical considerations. Early Education and Development 17 (1): 4-41.

UNICEF. 2012. School Readiness: a conceptual framework. New York: United Nations Children's Fund.

Yarker, P. 2016. 'Everyone's educational future is always in the making: Learning without Limits'. In The Mismeasurement of Learning: How tests are damaging children and primary education. pp. 30-31. https://www.teachers.org.uk/sites/default/files2014/mismeasurement-40pp-a4-10827-.pdf. Accessed 27 Jan 2017.

Urban, M. 2017. We need meaningful, systematic evaluation, not a preschool PISA. Global Education Review 4 (2): 18-24.

Wood, E., and H. Hedges. 2016. Curriculum in early childhood education: critical questions about content, coherence, and control. The Curriculum Journal 27 (3): 387-405. 